\title{
The development and validation of the CARe Burn Scale: Child Form: a parent-proxy-reported outcome measure assessing quality of life for children aged 8 years and under living with a burn injury
}

\author{
Catrin Griffiths ${ }^{1}$ (1) $\cdot$ Ella Guest ${ }^{1} \cdot$ Timothy Pickles $^{2} \cdot$ Linda Hollèn $^{3} \cdot$ Mariusz Grzeda $^{1} \cdot$ Philippa Tollow $^{1}$. \\ Diana Harcourt ${ }^{1}$
}

Accepted: 30 August 2020 / Published online: 9 September 2020

(c) The Author(s) 2020

\begin{abstract}
Purpose Patient-reported outcome measures (PROMs) identify patient needs and therapeutic progress. This paper outlines the development and validation of the CARe Burn Scale: Child Form, a parent-proxy-reported outcome measure that assesses quality of life in children aged 8 and under living with a burn injury.

Methods A literature review and interviews with 12 parents of children with a burn and seven health professionals informed the development of a conceptual framework and draft PROM. Cognitive debriefing interviews with 18 parents and eight health professionals provided feedback to ascertain content validity, and 311 parents took part in field testing. Rasch and traditional psychometric analyses were conducted to create a shortened version. Further psychometric analyses with 133 parents tested the shortened CARe Burn Scale in relation to other parent-proxy measures.

Results The final conceptual framework included 5 domains: Social and Emotional Difficulties, Social and Emotional WellBeing, Wound/Scar Discomfort, Wound/Scar Treatment and Physical Abilities. Two scales fulfilled Rasch and traditional psychometric analyses, providing evidence of construct validity, acceptability, and reliability. Three scales did not fulfil the Rasch criteria and were retained as checklists. Compared to other parent-proxy measures, individual CARe Burn Scales correlated moderately with similar constructs and had low correlations with dissimilar constructs, indicating evidence of criterion validity (concurrent and discriminant).

Conclusions The CARe Burn Scale: Child Form can be used to measure children's quality of life after having a burn injury which can inform rehabilitation and surgical decision-making.
\end{abstract}

Keywords Parent $\cdot$ Paediatric $\cdot$ Child $\cdot$ PROM $\cdot$ Burn $\cdot$ Rasch

The British Burns Association Annual Conference 2017 presented dat the Royal College of Surgeons, London.

Electronic supplementary material The online version of this article (https://doi.org/10.1007/s11136-020-02627-x) contains supplementary material, which is available to authorized users.

Catrin Griffiths

catrin.griffiths@uwe.ac.uk

1 Centre for Appearance Research (CAR), Department of Health and Social Sciences, University of the West of England, Frenchay Campus, Coldharbour Lane, Bristol BS16 1QY, UK

2 Centre for Trials Research (CTR), Cardiff University, Cardiff, UK

3 Centre for Academic Child Health, Bristol Medical School, University of Bristol, Bristol, UK

\section{Introduction}

Burn injuries are the fourth most common cause of trauma in the world, with 11 million people requiring medical intervention including surgery each year [1]. Children under 5 years of age are at the greatest risk of burn injuries as they physically develop and become increasingly active, impulsive, and curious, but lack awareness [2, 3].

Scarring and physical impairment are common with burns [4]. Irrespective of a child's age, a burn can have a significant psychosocial impact, both for the child and family members [5]. Many undergo numerous surgical and rehabilitation interventions to improve wound healing and scarring, which can be physically and emotionally challenging [6]. Children can struggle with coming to terms with the traumatic event, while changes in physical appearance, pain, 
restricted physical abilities and adherence to treatments such as dressing changes can be hard to cope with [7-9]. Collecting and effectively using health-related patient-reported outcome data (PROM) are vital during surgical and rehabilitation decision-making in burn care since it pin-points how burn scars impact health and, consequently, how intervention may improve these outcomes. Yet the UK's National Burn Care Review (2001) [10] highlighted the lack of systematic assessment of burn patients' experiences of their treatment, scarring and psychosocial functioning, and emphasised that the development of new PROMs for this population was vital to support decision-making regarding care, including rehabilitation and reconstructive surgery. Parent-proxy measures are deemed most appropriate to capture young children's outcomes after burn injuries, since children under the age of 8 are not considered to have the skills needed to express complex concepts such as thoughts and feelings and to answer PROMs reliably [11].

Some validated parent/caregiver-proxy measures specifically assessing quality of life and health outcomes for children aged 8 and under with a burn are available [12]. These include the Children's Burns Outcome Questionnaire for children aged 5 years and under (CBOQ) [13] and the Brisbane Burn Scar Impact Profile (BBSIP) for caregivers of children aged less than 8 years [14]. However, there are certain aspects relating to a child's health when living with a burn that are not included in existing PROMs. For example, their questions are not specific to burn scars [13], they do not include the positive emotional well-being of a child living with a burn $[13,14]$ or do not include the wound stage of a burn injury $[13,14]$, which is essential information for treatment decision-making and care. The development of parent-proxy measures remains a priority in order to assess children's needs at any stage of burn recovery in order to inform surgical and rehabilitation decision-making [15].

This paper outlines the development and validation of the CARe Burn Scale: Child Form, a burn-specific parent/carerproxy reported outcome measure to assess quality of life for children aged 8 and under who have had a burn.

\section{Methods}

The CARe Burn Scale: Child Form was developed following an established three-stage development and validation process [16-19], considered the gold standard for developing and evaluating PROMs. This involved item generation (developing a conceptual framework using a literature review, qualitative interviews with patients and expert opinion), item reduction (using psychometric criteria such as Rasch analysis), and psychometric evaluation.

Ethical approvals were obtained from the University of the West of England and NHS Research Ethics
Committees. Informed consent was obtained from all individual participants included in the study.

\section{Stage 1: Conceptual framework development}

Semi-structured interviews were conducted with parents or carers of children aged 8 and under who had experienced a burn and burn-specialist health professionals to explore, in-depth, the impact of a burn on a child's health and wellbeing. When this paper refers to parents, this also includes carers who are not the child's parent but are still legally responsible for caring for the child such as foster parents or other family members. Face-to-face/telephone interviews were conducted between April 2013 and October 2013, recorded, transcribed verbatim and subjected to a thematic analysis [20]. A conceptual framework developed from these findings outlined the key aspects of a child's well-being when living with a burn.

\section{Stage 1.2: Item generation, initial scale formation, and pre-testing}

Using the health professional and parent/carer interview data, an extensive list of items was created for each conceptual framework domain, using parents' own words or phrases to increase the content validity of the items. A literature review of PROMs used in paediatric burn care was conducted, relevant parent-proxy measures were obtained, reviewed, and items included in these scales that were not discussed in the interviews were added to the measure. Psychosocial specialists from UK burn services provided feedback on the measure to ensure it was comprehensive.

Cognitive debriefing interviews $[16,19]$ were conducted with parents who reviewed the scale and gave feedback on their understanding of the items and the response categories, and they suggest new items to ensure that the scale had good face validity and was relevant and understandable to parents [21].

\section{Stage 2: Item reduction}

The measure was field-tested in 11 NHS Burn Services with parents of children aged 8 and under who had sustained a burn injury (of any size and location on their body) and could read English sufficiently well to complete the questionnaire. Eligible participants were invited to take part while attending hospital clinics or questionnaires were mailed to them. Questionnaires could be completed on paper or online, via a secure survey link (www.qualtrics. com). 


\section{Rasch measurement psychometric analysis}

Item reduction was informed by the Rasch measurement model/analyses [22-27] using RUMM2030 [28] based on the following criteria which the authors have previously reported in the development of a burn-specific PROM for adults with a burn injury [29].

\section{Item fit statistics}

Rasch analysis tests whether the observed data are consistent with the responses predicted by the Rasch model. Two indicators were investigated: (1) item-trait interaction (a non-significant $(p$ value $>0.05$ ) chi-square value would indicate negligible deviation between the collected data and expectations of the model); (2) the residual for each item in the range of -2.5 to +2.5 and non-significant chi-square values (Bonferroni-adjusted significance level of 0.01) indicates good fit.

\section{Person separation index (PSI)}

The PSI assesses whether the measurement of participants is reliably separated. A value of 0.7 or higher suggests the possibility to distinguish at least two groups of patients [30,31].

\section{Local dependency}

A residual correlation $>0.3$ above the mean residual correlation (of all item pairs for that scale) shows a problem with fit [32].

\section{Unidimensionality}

Smith's procedure [33] was used to measure unidimensionality within individual scales. This identifies if the person estimates derived from the most diverse subsets of items are significantly different. If the proportion, or the lower bound of the 95\% confidence interval of significant $(p<0.05) t$ tests, is less than $5 \%$ it indicates unidimensionality.

\section{Differential Item Functioning}

Differential Item Functioning analysis (DIF) [34] assesses whether item parameters remain invariant across different groups of patients. Item difficulties were compared across the following: age (split based on median: $0-2$ vs 3-8 years), gender (male vs female), burn type (burn wound vs burn scar only vs no wound/scar), and body part affected ('hands, bottom, upper legs, lower legs, feet' vs 'head/face, neck, chest, back, lower arms, upper arms). This analysis investigated the issue of possible bias from misfit of the data to model. Uniform and non-uniform DIF were investigated graphically (inspection of item characteristic curves (ICCs) for different groups) and by results of analysis of variance (Bonferroniadjusted significance level of 0.05 ).

\section{Targeting and item locations}

Graphical comparisons of the item distributions and person locations determined whether they covered more or less the same areas of the Rasch continuum. Large floor and ceiling effects indicates the inability to differentiate between participants along the construct [35].

\section{Item thresholds}

For each item, the use of response categories scored with successive integer scores indicated a continuum of increasing impact. This assumption was tested by ordering the thresholds specified by the Rasch analysis.

\section{Traditional psychometric analysis (Classical Test Theory)}

Traditional psychometric analysis using Classical Test Theory (CTT) was conducted using SPSS Statistics 23 [36] to show how the scale operates based on the CTT criteria: Cronbach's alphas and item-total correlations.

\section{Stage 3: Further psychometric evaluation}

Using the same recruitment methods and criteria as in Stage 2 , the final scale was tested in comparison to other parentproxy measures to ascertain evidence of criterion validity (concurrent and discriminant) [17]. Participants who had previously taken part in Stage 2 were also invited to take part. Stata v.15.1 [37] was used to test data quality, scaling assumptions, and validity and reliability:

Criterion validity: The individual scales from the CARe Burn Scale: Child Form were compared with existing parent-proxy measures of similar constructs (Paediatric Quality of Life Inventory (PedsQL) [38] and the Patient and Observer Scar Scale (POSAS-Observer Form) [39], which have previously used in burn care and research. The CARe Burn Scales were hypothesised to have moderate/high correlations with related constructs and low/no correlations with dissimilar constructs. Criteria were used as guides in terms of the magnitude of correlations, rather than pass/fail benchmarks (high correlation, $r<0.70$; and moderate correlation, $r<0.30$ to 0.70 ). 
It was hypothesised that:

- Wound/Scar Discomfort, Wound/Scar Treatment, Physical Difficulties, and Physical Abilities would moderately correlate with the PedsQL Physical Functioning subscale.

- Social Situations and Avoidance Behaviours would moderately correlate with the PedsQL Social Functioning subscale.

- Social and Emotional Difficulties and Social and Emotional Well-being would moderate correlate with the PedsQL Social Functioning and Emotional Functioning subscales.

- Trauma Symptoms would moderately correlate with the PedsQL Emotional Functioning subscale.

- Nursery/School would moderately correlate with the PedsQL School Functioning subscale.

- Child's Wound/Scar Dissatisfaction and Parent Dissatisfaction with the Appearance of Wounds/Scars would moderately correlate with the POSAS.

Traditional psychometric measurement properties were also examined: acceptability [percentage of missing data $(<10 \%$ acceptable)], internal consistency (Cronbach's alpha $(>0.70$ acceptable $)$, and acceptable item-total correlations $(>0.30)$.

The relationships between CARe Burn Scale subscales and sociodemographic and burn-related variables (age, gender of child and parent, ethnicity, marital status, cause of burn and time since burn) were examined using regression analyses to determine the extent to which scores were influenced by these variables.

\section{Results}

\section{Stage 1.1: Conceptual framework formation}

Twelve parents ( 9 female, $80 \%$ White ethnicity, see Table 1) and seven clinical psychologists who worked in paediatric burn care were interviewed (analysis of these interviews is reported in full in Guest et al., [15] and Griffiths et al. [40]). Thematic analysis identified a range of themes. Thirteen key domains formed the initial conceptual framework reflecting a child's quality of life after a burn:
1. Wound/Scar Discomfort
2. Physical Difficulties
3. Physical Abilities
4. Physical Development
5. Wound/Scar Treatment
6. Social Situations
7. Avoidance Behaviours
8. Social and Emotional Difficulties
9. Social and Emotional Well-Being
10. Child's Wound/Scar Dissatisfaction
11. Parent Dissatisfaction with the Appearance of Wounds/ Scars
12. Trauma Symptoms
13. Nursery/School

\section{Stage 1.2: Item generation, initial scale formation, and pre-testing}

Initially, 121 items were created. Cognitive debriefing interviews were conducted with 18 parents of children aged $0-8$

Table 1 Stage 1: Qualitative interview study participant demographics

\begin{tabular}{llllllll}
\hline$N$ & Age & Ethnicity & Cause of burn & Body parts affected by burn & Age child was injured & Child's age now & Time since burn injury \\
\hline P1 & 34 & Asian & Flame & Arms, legs, face, neck, back & 2.5 years & 8 years old & 5.5 years \\
P2 & 40 & White & Flame & Legs & 5 years old & 7 years old & 1 year and 9 months \\
P3 & 45 & White & Flame & Legs & 5 years old & 7 years old & 1 year and 9 months \\
P4 & 52 & White & Flame & Chest, arms, back and neck & 3 years old & 5 years old & 13 months \\
P5 & 53 & White & Flame & Chest, arms, back and neck & 3 years old & 5 years old & 13 months \\
P6 & 37 & White & Liquid & Face, neck and chest & 5 years old & 8 years old & 3 years \\
P7 & 28 & White & Flame & Chest, stomach, neck, face, arms & 5 years old & 8 years old & 3 years \\
P8 & 28 & White & Flame & Chest, stomach, neck, face, arms & 5 years old & 8 years old & 3 years \\
P9 & 39 & White & Liquid & Chest, face, arms, legs and feet & 1.5 years old & 12 years old & 10 years \\
P10 & 40 & White & Flame & Face, ear, shoulder and back & 11 years old & 12 years old & 12 months \\
P11 & 38 & Black & Contact & Left leg & 6 months old & 11 years old & 10 years and 6 months \\
P12 & 42 & Black & Contact & Arm and hand & 6 months old & 11 years old & 10 years and 6 months \\
\hline
\end{tabular}

$N=$ participant number 
with a burn (83\% female, mean parent age: 41:19, SD: 6.34, mean child age when injured: 3.91, SD: 2.84), and feedback was sought from eight health professionals (six clinical psychologists, one play specialist, one health psychologist) resulting in minor edits (changes to item wording, providing more burn-specific examples) and a further 29 items being added to the existing domains.

Health professionals reviewed and provided feedback on the scale and changes were made in light of their responses. Parents then reviewed the amended scale, which was edited after each interview in response to the feedback, to ensure that subsequent parents were reviewing the most recent version. A total of 150 items were then field-tested.

\section{Stage 2: Field testing, item reduction and Rasch analysis}

\section{Sample}

A total of 311 participants completed the CARe Burn Scale: Child Form. Table 2 provides the participant characteristics. The largely supported rule of thumb is that in order to perform an accurate and precise Rasch analysis with over $99 \%$ confidence and item calibrations within \pm 0.5 logits, a sample size of 250 is needed [41].

\section{Item reduction and scale formation}

The original scale field-tested had 150 items. During the item reduction stage, 124 items were dropped, which resulted in 26 items in the final scale. Rasch analysis identified a solution for three out of the 13 scales (Parent Dissatisfaction with the Appearance of Wounds/Scars, Social and Emotional Difficulties and Social and Emotional Well-being).

However, based on reviewer feedback of this manuscript, Parent Dissatisfaction with the Appearance of Wounds/Scars was deemed to not reflect a true parent-proxy scale since it involved parents reporting their own feelings about their child's scarring, rather than reporting on their child's health after a burn. This subscale was therefore removed, which resulted in the final measure having two scales where as Rasch solution was found.

Seven of the 10 scales where a Rasch solution was not found were dropped (Physical Difficulties, Physical Development, Social Situations, Avoidance Behaviours, Child's Wound/Scar Dissatisfaction, Trauma Symptoms and Nursery/School). Three (Wound/Scar Discomfort, Physical Abilities, Wound/Scar Treatment) were retained based on theoretical insight via communication with burns clinicians who reported during the item reduction stage that these scales would be still useful in their clinical practice. For further information about the checklists, please see below.
Table 2 Stage 2: Study patient characteristics $(N=311)$

\begin{tabular}{|c|c|c|c|}
\hline \multicolumn{4}{|l|}{ Demographics } \\
\hline & & $N$ & $\%$ \\
\hline $\begin{array}{l}\text { Child's age in years } \\
\text { when injured }\end{array}$ & $M=2.0(\mathrm{SD}: 1.84)$ & 307 & \\
\hline \multirow[t]{2}{*}{ Child's gender } & Male & 173 & 55.6 \\
\hline & Female & 135 & 43.4 \\
\hline \multirow[t]{4}{*}{ Injury status } & Burn wound & 14 & 4.5 \\
\hline & Burn scar & 172 & 55.3 \\
\hline & Both wound and scar & 24 & 7.7 \\
\hline & No wound scar & 94 & 30.2 \\
\hline \multirow[t]{11}{*}{ Body part affected } & Head or face & 89 & 28.6 \\
\hline & Neck & 71 & 22.8 \\
\hline & Chest & 117 & 37.6 \\
\hline & Back & 28 & 9.0 \\
\hline & Lower arms & 60 & 19.3 \\
\hline & Upper arms & 84 & 27.0 \\
\hline & Hands & 114 & 36.7 \\
\hline & Bottom & 10 & 3.2 \\
\hline & Upper legs & 37 & 11.9 \\
\hline & Lower legs & 23 & 7.4 \\
\hline & Feet & 34 & 10.9 \\
\hline \multirow[t]{3}{*}{ Parent gender } & Male & 43 & 13.6 \\
\hline & Female & 262 & 82.6 \\
\hline & Missing & 12 & 3.8 \\
\hline
\end{tabular}

Percentages in the above table may not sum to $100 \%$ as they show the share of given group in the whole sample of 311 burn patients

The final scale has 26 items and 5 scales: Social and Emotional Difficulties, Social and Emotional Well-being, Wound/Scar Discomfort, Physical Abilities, and Wound/ Scar Treatment.

\section{Rasch measurement psychometric analysis}

In the final version of the CARe Burn Scale: Child Form, a Rasch solution was identified for two scales (Table 3): Social and Emotional Difficulties and Social and Emotional Wellbeing. 25 items across those two scales were reduced to 15 based on item reduction implemented via Rasch analyses. Scale reliability was generally supported by high PSI. Fit to the Rasch model was good, with all item-trait interactions non-significant and no items with fit residuals out of range or presenting significant $X^{2}$ values. All final scale solutions contain no items with reversed thresholds. One Social and Emotional Difficulties item displayed non-uniform DIF for age, but its inclusion allowed for overall fit to the Rasch model and higher reliability, so the decision was made to keep it. The vast majority of items did not exhibit DIF, indicating that items remain invariant across different groups of patients. However, both solutions required response 


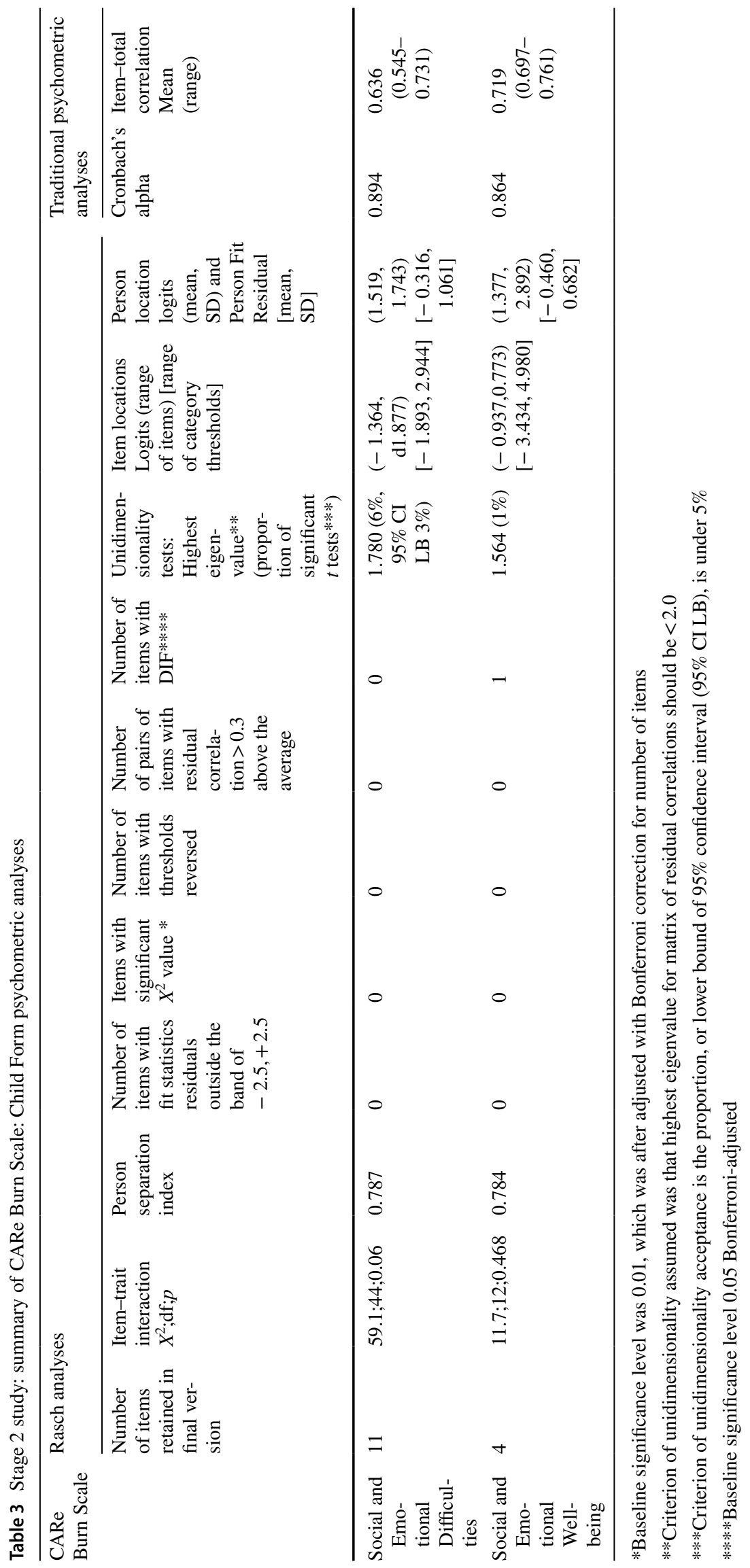


thresholds to be collapsed for this to be the case. For Social and Emotional Difficulties, the third, fourth, and fifth categories (Some of the time, Most of the time and All of the time) were collapsed, and for Social and Emotional Well-being, the first, second, and third categories (None of the time, A little of the time, Some of the time) were collapsed. All pairs of items within each scale had a residual correlation less than 0.3 above the mean (of all item pairs for that scale), supporting local independence among items. Smith's procedure [33] confirmed unidimensionality for all three scales.

Despite finding two solutions, all scales had gaps in the person location and item threshold distributions, meaning that it is not possible to wholly reflect the range of the continuum, and ceiling effects in their person distributions. The results showed that Social and Emotional Well-being had one item with non-uniform DIF on age, though the evidence for these DIF issues is weak ( $p$ value just less than the $\alpha=0.05$ Bonferroni-corrected level) but are reported for full disclosure. For Wound/Scar Discomfort, an item displayed DIF on burn type, plus there was poor reliability, a ceiling effect, and overall misfit. For Physical Difficulties, multiple items had multiple issues with combinations of model fit and DIF on gender and burn type and body part affected, with poor reliability, a ceiling effect, and overall misfit. For Physical Abilities and Wound/Scar Treatment, there was poor reliability and a ceiling effect. For Physical Development, several items had multiple issues with combinations of model fit and local independence, with poor reliability, a ceiling effect, and overall misfit. For Social Situations, there was poor reliability, a ceiling effect, and overall misfit. For Avoidance Behaviours, several items had multiple issues with combinations of model fit, local dependence, and DIF on age, with poor reliability and a ceiling effect. For Child's Wound/Scar Dissatisfaction, an item displayed DIF on burn type, plus there was poor reliability and a ceiling effect. For Trauma Symptoms, no model would converge given the items and data within them. For Nursery/School, multiple items had multiple issues with model fit, plus there was poor reliability and a ceiling effect.

\section{Traditional psychometric analyses (Classical Test Theory)}

All scales with Rasch solutions passed criteria for reliability (Cronbach's alpha $>0.80$ ) and validity (all item-total correlation coefficients $>0.30$ ) (Table 3 ).

\section{Checklists}

Seven of the 10 scales that did not meet Rasch criteria were removed from the PROM and three were retained based on theoretical insight. During the analysis stage, we communicated with health professionals involved in the pre-testing study and they recommended retaining the Wound/Scar
Treatment, Wound/Scar Treatment, and Physical Abilities scales as they would be still useful in their clinical practice.

The checklists are scored by summing all items within them. They can be used by clinicians and researchers to ascertain further information about the domain being examined. However, since they are not psychometrically valid, they are not intended for use in psychometric analysis. Within the three retained scales, 'Not at all' was the most commonly endorsed response category for items in Wound/ Scar Treatment, while 'Not at all' and 'All of the time,' respectively, were the most commonly endorsed categories in the Wound/Scar Discomfort and Physical Abilities scales (Table 4).

\section{Stage 3: Further psychometric evaluation}

\section{Sample}

133 parents took part in further psychometric testing part (19 men, 105 women representing 55 girls and 67 boys, gender not provided for 11 parents and children). Child's mean age when injured was 4.0 years (SD: 2.1) (see Table 5).

\section{Traditional psychometric analyses}

All scales exceeded criteria for validity and reliability (Table 6 and Appendix A-Supplementary Material). Internal consistency was supported by high Cronbach's alpha coefficients $(>0.85)$. Item-total correlations (range of means, 0.53 to 0.75 ) were also high. Missing data were slightly higher than $10 \%$ for all items (range 14\%-16\%). A comparison of the results with and without missing data showed that the difference in Cronbach's alphas was negligible (Appendix B-Supplementary Material).

The individual subscales in the CARe Burn Scale: Child Form and the other parent-proxy measures were correlated providing evidence of criterion validity (concurrent) (Appendix C-Supplementary Material). The CARe Burn Scales correlated moderately with most of the PedsQL subscales. In particular, Social and Emotional Difficulties correlated moderately with all of the PedsQL subscales. Social and Emotional Well-Being was moderately correlated with the PedsQL Social and Psychosocial Health subscales.

As predicted, Social and Emotional Well-being had low correlations with the PedsQL Physical Functioning subscale, which provides evidence of discriminant validity. An unexpected moderate correlation was identified between Social and Emotional Difficulties and the PedsQL Physical Functioning subscale.

Regression analysis identified significant relationships between two of the individual CARe Burn Scales and sociodemographic variables (Appendix D-Supplementary Material). Older age and shorter time since burn were both 


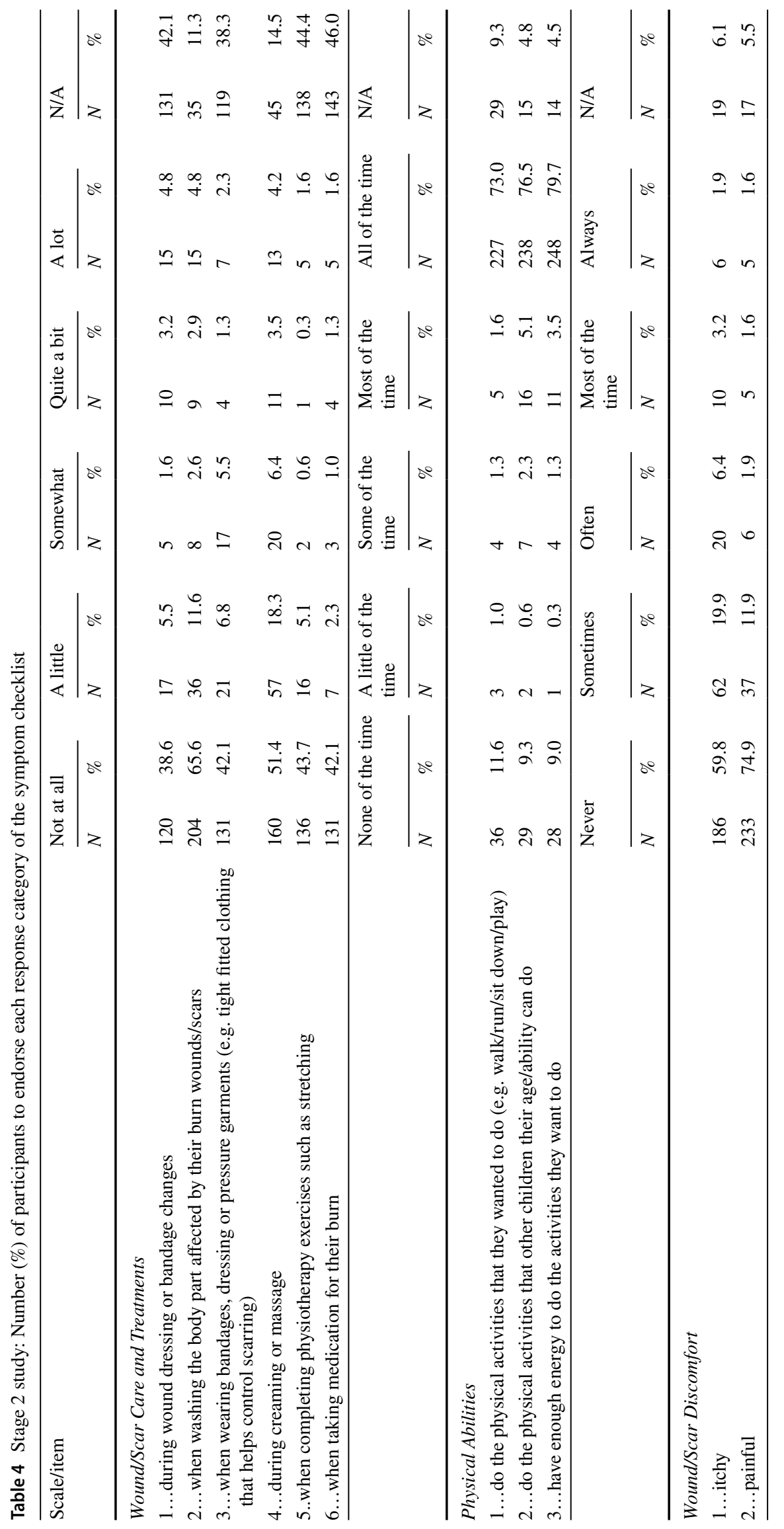


Table 5 Stage 3: Patient characteristics study $2(\mathrm{~N}$ total $=133)$

\begin{tabular}{|c|c|c|}
\hline Characteristics & Value & $N$ \\
\hline Child's age in years now (Mean, SD) & $4.0(2.1)$ & 124 \\
\hline Child's age in years at time of injury (Mean, SD) & $2.5(1.5)$ & 121 \\
\hline \multicolumn{3}{|l|}{ Time in years since burn } \\
\hline Mean (SD) & $1.6(1.5)$ & 121 \\
\hline Range & $0-7$ & \\
\hline \multicolumn{3}{|l|}{ Child's gender } \\
\hline Male & $67(54.9 \%)$ & 122 \\
\hline Female & $55(45.1 \%)$ & \\
\hline \multicolumn{3}{|l|}{ Parent gender } \\
\hline Male & $19(15 \%)$ & 133 \\
\hline Female & $114(85 \%)$ & \\
\hline \multicolumn{3}{|l|}{ Parental age } \\
\hline Mean (SD) & $35.2(6.3)$ & 105 \\
\hline Range & $21.0-63.8$ & \\
\hline Parental ethnicity & & 123 \\
\hline White British & $97(78.9 \%)$ & \\
\hline White other & $11(8.9 \%)$ & \\
\hline Indian & $4(3.3 \%)$ & \\
\hline Other & $4(3.2 \%)$ & \\
\hline Pakistani & $2(1.6 \%)$ & \\
\hline Chinese & $2(1.6 \%)$ & \\
\hline Black/Black British: Caribbean & $1(0.8 \%)$ & \\
\hline Black African & $1(0.8 \%)$ & \\
\hline Mixed & $1(0.8 \%)$ & \\
\hline Parental marital status & & 124 \\
\hline Married & $83(66.9 \%)$ & \\
\hline Civil partnership & $3(2.4 \%)$ & \\
\hline Single, never married & $16(12.9 \%)$ & \\
\hline Separated & $4(3.2 \%)$ & \\
\hline Divorced & $0(0.0 \%)$ & \\
\hline Cohabiting & $16(12.9 \%)$ & \\
\hline In relationship but not living together & $2(1.6 \%)$ & \\
\hline Cause of burn & & 125 \\
\hline Flame & $1(0.8 \%)$ & \\
\hline Liquid & $76(60.8 \%)$ & \\
\hline Contact & $39(31.2 \%)$ & \\
\hline Electricity & $0(0.0 \%)$ & \\
\hline Chemical/acid & $1(0.8 \%)$ & \\
\hline Other & $8(6 \%)$ & \\
\hline Body part burnt* & & 133 \\
\hline Head & $39(29.3 \%)$ & \\
\hline Neck & $28(21.0 \%)$ & \\
\hline Chest & $42(31.6 \%)$ & \\
\hline Back & $11(8.3 \%)$ & \\
\hline Lower arms & $26(19.6 \%)$ & \\
\hline Upper arms & $30(22.6 \%)$ & \\
\hline Hands & $52(39.1 \%)$ & \\
\hline Bottom & $3(2.3 \%)$ & \\
\hline Upper legs & $15(11.3 \%)$ & \\
\hline Lower legs & $12(9.0 \%)$ & \\
\hline Feet & $17(12.8 \%)$ & \\
\hline
\end{tabular}

*Does not add up to $100 \%$ since participants could have one or more body parts burnt. $N=$ number of participants
Table 6 Stage 3: Traditional psychometric analyses

\begin{tabular}{llll}
\hline \multicolumn{3}{l}{ Traditional psychometric analyses-reliability } & \\
\hline Scales & $N$ items & $\begin{array}{l}\text { Cronbach's } \\
\text { alpha }\end{array}$ & CITC (mean, range) \\
\hline $\begin{array}{l}\text { Social and } \\
\text { emotional dif- }\end{array}$ & 11 & 0.86 & $0.53,0.27-0.71$ \\
$\quad \begin{array}{l}\text { ficulties } \\
\text { Social and } \\
\text { emotional } \\
\text { well-being }\end{array}$ & 4 & 0.86 & $0.71,0.67-0.75$ \\
\hline
\end{tabular}

CITC Corrected Item-Total Correlation, only provided for scales with $>2$ subscales

associated with more social and emotional difficulties. Parents of girls were more likely to report that their child had higher levels of social and emotional well-being. However, since the majority of regression coefficients (15 out of 18 ) were non-significant, this provides evidence of discriminant validity.

\section{Discussion}

Parents played a vital role in the development of this new PROM, informing item generation and reviewing draft versions of the scale. The final domains and items included in the CARe Burn Scale: Child Form have therefore been verified by parents as important to a child's health and wellbeing after experiencing a burn injury. The CARe Burn Scale: Child Form is an important addition to the very few existing parent-proxy measures of a child's health after a burn, since it is the first burn-specific PROM to include both the wound and scar stages of recovery and to include the positive aspects of a child's social and emotional health when living with a burn.

Parent reports are vital when investigating quality of life for children who are still too young to reliably report complex issues such as their thoughts and feelings; however, they must be treated as a different perspective to the child's own. Most children over the age of 8 with a burn can reliably report their own health using PROMs developed for their age group, such as the CARe Burn Scale: Young Person Form [42].

During the item reduction stage, the number of domains in the scale was reduced substantially from 13 to 5 . All of the original domains were highlighted by parents/caregivers as important to a child's health when living with a burn injury during the item generation stage (i.e. in the qualitative interviews and cognitive debriefing interviews) and, ideally, all domains would be retained. However, the rationale for developing this parent-proxy was to develop a robust measure of health outcomes for children who are living with 
burn injuries, so it was imperative for the scales to work psychometrically. When a scale is psychometrically robust, it increases the chances that the scale will be able to identify clinical changes [22]. Our aim was also to produce a measure which was as short as possible for practical use in busy burns clinics, focussed on domains that are valid for the majority of parents/caregivers and are likely to detect clinical changes. We followed the three-stage PROM development and validation process [18], which recommends using Rasch analysis for item reduction, which identified only the scales that were psychometrically robust. Although a limitation of using this technique is that the final scale does not cover the full scope of quality of life contained within the original scale, three additional checklists focussing on physical health were retained to rebalance the breadth of the scale. Taken together, the subscales and checklists provide a valuable insight into the issues deemed important for a child's health when living with a burn reported in this and previous studies [12].

Although the checklists are not intended to be used in psychometric analysis, they can be used by clinicians to gain more information about a child's health. This is particularly important during treatment planning. Also the two psychological and behavioural scales that were retained based on the Rasch analysis (Social and Emotional Well-being and Social and Emotional Difficulties) are likely to pick up the psychological and social disturbances and adjustment related to physical health problems such as wound/scar pain/discomfort and physical health challenges that children often experience $[2,7,12]$.

Other existing parent-proxy measures of a child's health after a burn injury such as the CBOQ [13] and the BBSIP [14] do include the negative emotional impact on the children. However, the CARe Burn Scale - Child Form, is the only scale to include a domain to measure the positive side of a child's social and emotional health (Social and Emotional Well-being) in addition to the negative social and emotional impact (Social and Emotional Difficulties). Measuring both the negative and positive social and emotional impact is essential in order to gain a comprehensive assessment of the long-term impact on a child. The CARe Burn Scale - Child Form offers clinicians and researchers an additional tool to evaluate the impact of children's burns and treatment effectiveness.

\section{Limitations}

Although the regression analysis indicated that the gender or ethnicity of parents did not significantly influence the results, the sample was still relatively homogeneous in terms of gender and ethnicity, with most participants being White females. This limits the generalizability of the results. Future research should include more ethnically diverse samples and men.

Further ongoing validation work is still required. Specifically, test-retest reliability and responsiveness data are needed to explore the reliability of the scale and its ability to detect clinical changes over time. This is necessary in order that suitably validated PROMs are available to enable burn care teams to measure the effectiveness of treatment and surgery from a parent's perspective.

The scale described in this paper is only valid for measuring outcomes for children aged 8 and under with a burn, but it is part of a suite of burn-specific PROMs developed by the authors that assess outcomes of young people aged 8-17 years [42], adults [29], and parents who are supporting a child with a burn [43].

\section{Conclusions}

The CARe Burn Scale: Child Form is now available for health professionals and researchers use to identify the needs of children aged 8 years and under following a burn injury. Visit www.careburnscales.org.uk to access the full set of CARe Burn Scales.

Acknowledgements We would like to thank all the parents who contributed to studies in this paper and the health professionals who helped with recruitment and/or gave their feedback on the initial measure.

Funding This work is part of a programme of research that has been funded by Restore Burn and Wound Research, the Scar Free Foundation Centre for Children's Burns Research, Dan's Fund for Burns and the Scar Free Foundation. The views expressed are those of the authors, and not necessarily those of the funding bodies. Catrin Griffiths has nothing to disclose. Ella Guest has nothing to disclose. Timothy Pickles has nothing to disclose. Linda Hollèn has nothing to disclose. Mariusz Grzeda has nothing to disclose. Philippa Tollow has nothing to disclose. Diana Harcourt has nothing to disclose. None of the authors has a financial interest in any of the products, devices, or drugs mentioned in this manuscript.

\section{Compliance with ethical standards}

Conflict of interest Catrin Griffiths declares that he/she has no conflict of interest. Ella Guest declares that he/she has no conflict of interest. Tim Pickles declares that he/she has no conflict of interest. Linda Hollen declares that he/she has no conflict of interest. Mariusz Grzeda declares that he/she has no conflict of interest. Philippa Tollow declares that he/she has no conflict of interest. Diana Harcourt declares that he/ she has no conflict of interest.

Ethical approval All procedures performed in studies involving human participants were in accordance with the ethical standards of the institutional and national research committee (University of the West of England and NHS Research Ethics Committees; REC reference: 15/ SW/0263, IRAS project ID: 167766) and with the 1964 Helsinki declaration and its later amendments or comparable ethical standards. 
Informed consent Informed consent was obtained from all individual participants included in the study.

Research involving human and animal rights This article does not contain any studies with animals performed by any of the authors.

Open Access This article is licensed under a Creative Commons Attribution 4.0 International License, which permits use, sharing, adaptation, distribution and reproduction in any medium or format, as long as you give appropriate credit to the original author(s) and the source, provide a link to the Creative Commons licence, and indicate if changes were made. The images or other third party material in this article are included in the article's Creative Commons licence, unless indicated otherwise in a credit line to the material. If material is not included in the article's Creative Commons licence and your intended use is not permitted by statutory regulation or exceeds the permitted use, you will need to obtain permission directly from the copyright holder. To view a copy of this licence, visit http://creativecommons.org/licenses/by/4.0/.

\section{References}

1. World Health Organization. (2004). The global gurden of disease. Geneva: World Health Organization.

2. Bessey, P. Q., Arons, R. R., DiMaggio, C. J., \& Yurt, R. W. (2006). The vulnerabilities of age: Burns in children and older adults. Surgery, 140(4), 705-717.

3. Dhopte, A., Tiwari, V., Patel, P., \& Bamal, R. (2017). Epidemiology of pediatric burns and future prevention strategies-a study of 475 patients from a high-volume burn center in North India. Burns \& Trauma, 5(1), 1.

4. Stoddard, F. J., Ryan, C. M., \& Schneider, J. C. (2014). Physical and psychiatric recovery from burns. Surgical Clinics, 94(4), 863-878.

5. Hall, E., Saxe, G., Stoddard, F., Kaplow, J., Koenen, K., Chawla, N., et al. (2005). Posttraumatic stress symptoms in parents of children with acute burns. Journal of Pediatric Psychology, 31(4), 403-412.

6. Esselman, P. C. (2007). Burn rehabilitation: An overview. Archives of Physical Medicine, 88(12), S3-S6.

7. Green, E., Cadogan, J., \& Harcourt, D. (2018). A qualitative study of health professionals' views on using iPads to facilitate distraction during paediatric burn dressing changes. Scars, Burns \& Healing, 4, 2059513118764878.

8. McGarry, S., Elliott, C., McDonald, A., Valentine, J., Wood, F., \& Girdler, S. (2014). Paediatric burns: From the voice of the child. Burns, 40(4), 606-615.

9. King, I. C. (2018). Body image in paediatric burns: A review. Burns \& Trauma, 6(1), 12.

10. National Burns Care Review. (2001). Committee Report: Standards and Strategy for Burn Care: A Review of Burn Care in the British Isles. British Burn Association.

11. Bevans, K. B., Riley, A. W., Moon, J., \& Forrest, C. B. (2010). Conceptual and methodological advances in child-reported outcomes measurement. Expert Review of Pharmacoeconomics \& Outcomes Research, 10(4), 385-396.

12. Griffiths, C., Rumsey, N., Armstrong-James, L., White, P., Pleat, J. A., \& Harcourt, D. (2015). Systematic review of patient reported outcome measures used in child and adolescent burn research. Burns., 41(2), 212-224.

13. Kazis, L. E., Liang, M. H., Lee, A., Ren, X. S., Phillips, C. B., Hinson, M., et al. (2002). The development, validation, and testing of a health outcomes burn questionnaire for infants and children
5 years of age and younger: American Burn Association/Shriners Hospitals for Children. The Journal of burn care \& rehabilitation, 23(3), 196-207.

14. Tyack, Z., Ziviani, J., Kimble, R., Plaza, A., Jones, A., Cuttle, L., et al. (2015). Measuring the impact of burn scarring on healthrelated quality of life: Development and preliminary content validation of the Brisbane Burn Scar Impact Profile (BBSIP) for children and adults. Burns, 41(7), 1405-1419.

15. Guest, E., Griffiths, C., \& Harcourt, D. (2018). A qualitative exploration of psychosocial specialists' experiences of providing support in UK burn care services. Scars, Burns \& Healing, 4, 2059513118764881.

16. Klassen, A. F., Ziolkowski, N., Mundy, L. R., Miller, H. C., McIlvride, A., Dilaura, A., et al. (2018). Development of a new patientreported outcome instrument to evaluate treatments for scars: The SCAR-Q. Plastic and Reconstructive Surgery-Global Open, 6(4), e1672.

17. Aaronson, N., Alonso, J., Burnam, A., Lohr, K., Patrick, D., Perrin, E., et al. (2002). Assessing health status and quality-oflife instruments: Attributes and review criteria. Quality of Life Research, 11(3), 193.

18. Poulsen, L., McEvenue, G., Klassen, A., Hoogbergen, M., Sorensen, J. A., \& Pusic, A. (2019). Patient-reported outcome measures: BODY-Q. Clinics in Plastic Surgery, 46(1), 15-24.

19. Klassen, A. F., Cano, S. J., Scott, A., Snell, L., \& Pusic, A. L. (2010). Measuring patient-reported outcomes in facial aesthetic patients: Development of the FACE-Q. Facial Plastic Surgery, 26(4), 303.

20. Braun, V., \& Clarke, V. (2006). Using thematic analysis in psychology. Qualitative Research in Psychology, 3(2), 77-101.

21. Pusic, A. L., Klassen, A. F., Scott, A. M., Klok, J. A., Cordeiro, P. G., \& Cano, S. J. (2009). Development of a new patient-reported outcome measure for breast surgery: The BREAST-Q. Plastic and Reconstructive Surgery, 124(2), 345-353.

22. Wright, B. D. (1977). Solving measurement problems with the Rasch model. Journal of Educational Measurement, 14(2), 97-116.

23. Rasch, G. (1960). Studies in mathematical psychology: I. Probabilistic models for some intelligence and attainment tests. Chicago: The University of Chicago Press.

24. Rasch, G. (1966). An item analysis which takes individual differences into account. British Journal of Mathematical Statistical Psychology, 19(1), 49-57.

25. Andrich, D. (1978). Rating formulation for ordered response categories. Psychometrika, 43(4), 561-573. https://doi.org/10.1007/ Bf02293814.

26. Andrich, D. (1988). Rasch models for measurement. Sage University papers series Quantitative applications in the social sciences (Vol. 07-068). Newbury Park: Sage.

27. Andrich, D. (2002). Implications and applications of modern test theory in the context of outcomes based education. Studies in Educational Evaluation, 28(2), 103-121. https://doi.org/10.1016/ S0191-491X(02)00015-9.

28. Andrich, D., Sheridan, B., \& Lou, G. (2009). RUMM2030. Perth: RUMM Laboratory.

29. Griffiths, C., Guest, E., Pickles, T., Hollen, L., Grzeda, M., White, P., et al. (2019). The development and validation of the CARe Burn Scale-Adult Form: A Patient-Reported Outcome Measure (PROM) to assess quality of life for adults living with a burn injury. Journal of Burn Care \& Research, 40(3), 312-326. https ://doi.org/10.1093/jbcr/irz021.

30. Cronbach, L. J. (1951). Coefficient alpha and the internal structure of tests. Psychometrika, 16, 297-333.

31. Cronbach, L. J., \& Meehl, P. E. (1955). Construct validity in psychological tests. Psychological Bulletin, 52(4), 281-302. 
32. Christensen, K. B., Makransky, G., \& Horton, M. (2017). Critical values for Yen's Q 3: Identification of local dependence in the Rasch model using residual correlations. Applied Psychological Measurement, 41(3), 178-194.

33. Smith, E. V., Jr. (2002). Detecting and evaluating the impact of multidimensionality using item fit statistics and principal component analysis of residuals. Jr J Appl Meas, 3(2), 205-231.

34. Zwick, R. (2012). A review of ETS differential item functioning assessment procedures: Flagging rules, minimum sample size requirements, and criterion refinement. ETS Research Report Series, 2012(1), i-30.

35. Gothwal, V. K., Wright, T. A., Lamoureux, E. L., \& Pesudovs, K. (2010). Activities of Daily Vision Scale: What do the subscales measure? Investigative Ophthalmology and Visual Science, 51(2), 694-700

36. Corp, I. B. M. (2015). IBM SPSS Statistics for Windows, Version 23.0. Armonk, NY: IBM Corp.

37. StataCorp. (2017). Stata Statistical Software: Release 15. College Station, TX: Stata Corp LLC.

38. Varni, J. W., Seid, M., \& Rode, C. A. (1999). The PedsQL ${ }^{\text {TM: }}$ Measurement model for the pediatric quality of life inventory. Medical Care, 37(2), 126-139.

39. Draaijers, L. J., Tempelman, F. R., Botman, Y. A., Tuinebreijer, W. E., Middelkoop, E., Kreis, R. W., et al. (2004). The patient and observer scar assessment scale: A reliable and feasible tool for scar evaluation. Plastic and Reconstructive Surgery, 113(7), 1960-1965.

40. Griffiths, C., Guest, E., Grzeda, M., Rumsey, N., \& Harcourt, D. (2017). The development of the CARe Burn Scales. Paper presented at the British Burns Association Annual Conference 2017, Royal College of Surgeons.

41. Institute for Objective Measurement, Inc. (2019). Sample size and item calibration [or person measure] stability. Retrieved March 7, 2019, from https://www.rasch.org/rmt/rmt74m.htm.

42. Griffiths, C., Guest, E., Pickles, T., Hollen, L, Grzeda, M., Tollow, P., \& Harcourt, D. (in preparation). The development and validation of the CARe Burn Scale - Young Person Form for young people aged 8-17 affected by a burn injury.

43. Griffiths, C., Guest, E., Pickles, T., Grzeda, M., Tollow, P., \& Harcourt, D. (in preparation). The development and validation of the CARe Burn Scale - Parent Form for parents who are supporting a child with a burn injury.

Publisher's Note Springer Nature remains neutral with regard to jurisdictional claims in published maps and institutional affiliations. 